\title{
DE LOS MODELOS DE CIUDADANÍA SOLIDA A UN MODELO DE CIUDADANIA ALTERNANTE-INTERMITENTE
}

\author{
FROM THE MODELS OF SOLID CITIZENSHIP \\ TO A MODEL OF ALTERNATE-FLASHING CITIZENSHIP
}

\author{
Alejandro Klein* \\ Marcela Ávila Eggleton**
}

\begin{abstract}
RESUMEN
En este trabajo nos proponemos desarrollar algunas hipótesis en torno a la ciudadanía y su relación con la o las formas de contrato social y concomitantemente con las estructuras democráticas actuales. Su forma clásica se asocia al desarrollo de un modelo estatal de sociedad donde se vuelve imprescindible propiciar formas de elección y decisión que forman parte de la construcción de subjetividad en términos de madurez y adultez Simultáneamente, estas modalidades se asocian a formas de contrato social intrincadas a la garantía de un porvenir, existencia de garantías sociales y jurídicas y un marco ontológico mínimo. Por otra parte proponemos como otra hipótesis pensar una nueva forma de contrato social relacionada a modelos políticos impulsados por el neoliberalismo Desde este modelo suponemos que el vínculo social y la ciudadanía pasa por diferentes estados de forma intermitente, quizás relacionable a lo que Bauman sugiere como formas líquidas de lo social.
\end{abstract}

Palabras-clave: ciudadanía, Lazo social, Ciudadanía intermitente

\begin{abstract}
In this paper we propose to develop some hypotheses about citizenship and its relationship to the forms of social contract and concomitantly with existing democratic structures. Its classic form is associated with the development of a state model of society where it become simperative to promote choice and decision perspectives aspart of the construction of subjectivity in terms of maturity and adulthood Simultaneously, these modalities are associated with intricate forms of social contract to the guarantee of a social future,existence of social and legal guarantees and minimum ontological framework. Furthermore we propose as
\end{abstract}

\footnotetext{
* Psicologo. Dr em Trabalho Social pela Universidade Federal do Rio de Janeiro. Professor da Universidade de Guanajuato. Coordinador do Doutorado en Ciencias Sociais da Divisao de Ciencias Sociais da Universidade de Guanajuato. Coordinador do Grupo de Pesquisa Larna do Oxford Institute of Ageing. Faculty Member do Oxford Institute of Ageing, Oxford University E-mail: alejandroklein@hotmail.com

*** Doctor en Ciencia Política por la Universidad Nacional Autónoma de México. Actualmente se desempeña como Profesor-Investigador de la Facultad de Ciencias Políticas y Sociales de la Universidad Autónoma de Querétaro. Es autora del libro "La Representatividad en México. Evaluando los Sistemas Electorales Municipales" coautora de "Abstencionismo y Participación Electoral en México", asimismo ha publicado diversos capítulos de libros y artículos académicos.E-mail: maeggleton@hotmail.com
} 
another hypothes is to think a new form of social ontractrelated to political models driven by neoliberalism From this model we assume that the social bondand the citizenship passes through different states intermittently, perhaps relatable to what Bauman suggested as liquid patterns of the social.

Keywords: citizenship, Social bond, Citizenship intermittent

\section{Introduccion}

En este trabajo nos proponemos desarrollar algunas hipótesis en torno a la ciudadanía y su relación con la o las formas de contrato social y concomitantemente con las estructuras democráticas actuales.

Suponemos antes que nada que la ciudadanía admite formas de construcción en torno a prácticas discursivas y modelos sociales, culturales y subjetivos que le son inherentes. Su forma clásica se asocia al desarrollo de un modelo estatal de sociedad donde se vuelve imprescindible propiciar formas de elección y decisión que forman parte de la construcción de subjetividad en términos de madurez y adultez (KLEIN, 2006), (GIDDENS, 1997). Simultáneamente, estas modalidades se asocian a formas de contrato social intrincadas a la garantía de un porvenir, existencia de garantías sociales y jurídicas y un marco ontológico mínimo.

Por otra parte proponemos como otra hipótesis pensar una nueva forma de contrato social a la que denominamos descontractualización generalizada, relacionada a modelos políticos impulsados por el neoliberalismo (KLEIN, 2006). Desde este modelo suponemos que el vínculo social pasa por diferentes estados de forma intermitente, quizás relacionable a lo que Bauman sugiere como formas líquidas de lo social (BAUMAN, 1999). Estas formas inéditas de contrato social que propone el neoliberalismo, parecen indicar que los modelos de ciudadanía continúan vigentes, desaparecen o se ausentan de forma súbita y a veces brutal.

Cabe preguntarse de esta manera si las nuevas formas de democracia que parecen asentarse en la contemporaneidad, no implican -paradójicamenteformas de exclusión social. Las mismas estructuras (pensemos por ejemplo en Latinoamérica) que se encuentran en proceso de asentamiento democrático, sin embargo, no logran solucionar las estructuras de exclusión, que, por el contrario, parecen acentuarse y cronificarse (HELD, 1992; TILLY, 2007 ).

De esta manera ceden los sistemas de previsión y regulación social basados en las figuras de lo racional. Pero también el trinomio: democracia-inclusión-participación social cede o se reformula y ya no implica una correlación asegurada. Es decir: desde esta nueva forma de contrato social puede haber democracia sin participación y la misma participación ser una forma de exclusión social. Llegado al límite nos preguntamos inclusive si no estamos asistiendo a formas de participación social desde estructuras democráticas discursivamente pero inoperantes estructuralmente.

Proponemos llamar a esta modalidad de ciudadanía de: vínculo-no vínculo alternante intermitente.

\section{Presentación de la problemática de ciuda- danía}

Distintos autores (COUTINHO, 2000; VASCONCELOS, 1988) indican que la problemática de ciudadanía es inseparable de un soporte histórico relativamente preciso, inscripto en una prolongada lucha de diversos actores y organizaciones sociales pugnando por el derecho al voto, políticas sociales, reivindicaciones culturales, y otros.

Probablemente hablar de LA ciudadanía en general implique la misma ficción que hablar de LA modernidad con la misma amplitud. En tal sentido Marshall (1967) distingue tres elementos progresivos e históricos dentro del concepto de ciudadanía: derechos civiles, políticos y sociales. Los derechos civiles surgen en el siglo XVIII, en el siglo XIX los políticos $\mathrm{y}$, en el siglo $\mathrm{XX}$, los derechos sociales. Esta posición es criticable como una visión funcionalista que enfoca el cambio de una sociedad 
pre-industrial a otra industrial dentro de una perspectiva evolucionista (VASCONCELOS, 1988). Por otro lado, es necesario recalcar sus aspectos claramente ingenuos ${ }^{1}$ en el sentido de una marcha irreversible de la ciudadanía.

Sin embargo, cabe señalar que sus ideas expresan el consenso extendido en la modernidad keynesiana, de que los derechos sociales implican la impostergabilidad y el "derecho de participar integralmente en la herencia social" (VASCONCELOS,1988, p.27). La transmisión generacional y la biografía personal consolidan una estructura de continuidad y entrelazamiento social: el ciudadano es una persona que puede tener la expectativa razonable de logros en su tiempo personal, ajustados a un devenir social que le garantiza derechos. Probablemente se trata de una forma específica de lazo social, por el cual se establece una correlación no determinista entre lo social y lo psicológico. Este lazo social es eficaz en tanto enuncia una serie de garantías que operan al mismo tiempo como basamentos imprescindibles de la construcción de subjetividad ciudadana: porvenir, promesa, inclusión social.

Desde un contexto histórico preciso, la ciudadanía generada desde la matriz keynesiana se enlaza a un importante sentido de promesa, concretizable en mayor o menor grado, en distintas realizaciones a las que se puede llegar y participar en tanto se cumplan determinadas condiciones (por ejemplo: educación mínima, mayoría de edad, participación generalizada). Pero por otro lado, este proceso implica, además de posiciones política y económicas, una forma de subjetividad asentada en la capacidad de mentalizar situaciones y personas en forma de opciones y alternativas y con aceptación de las diferencias regidas por la ley: "El ciudadano es el tipo de sujeto forjado por un Estado que enuncia que la soberanía emana del pueblo (...) es un tipo subjetivo organizado por la suposición básica de que, real o potencialmente, la ley es la misma para todos" (LEWKOWICZ, 2004, p.57).

El desarrollo de la ciudadanía, en el sentido mencionado de promesa, como señala Vasconcelos (2008), “involucra la extensión de cada derecho

\footnotetext{
1 "En muchos países europeos varios de estos progresos recién ocurrieron en los últimos cincuenta años y frecuentemente en un orden inverso. Y aún en Inglaterra la evidencia histórica habla de un 'modelo de flujo y reflujo' más que de un esquema lineal” (Kymlicka-Norman, 1996, p. 5-8).
}

hasta incluir toda la población" (VASCONCELOS, 2008, p.91), como una práctica justa y razonable. Si la ley es la misma para todos, quiere decir que somos iguales ante la ley. Y ese sentido de igualdad se sintetiza en la idea de ciudadanía. Por tanto, la promesa primigenia es una promesa de igualdad, tanto en su punto de llegada como en su punto de partida.

Sin embargo, cabe señalar que estos derechos no son 'otorgados', sino que deben ser asimismo 'conquistados'. Coutinho (2000) acota que: "la generalización de los derechos políticos, hasta en el mismo nivel de sufragio, es el resultado de la lucha de la clase trabajadora" (COUTINHO, 2000, p.60):

Ciudadanía es la capacidad conquistada por algunos individuos, o (en el caso de una democracia efectiva) por todos los individuos, de apropiarse de los bienes socialmente creados, de actualizar todas las potencialidades de realización humana abiertas por la vida social en cada contexto históricamente determinado. (COUTINHO, 2000, p.50-51).

Por su parte, Kymlicka y Norman indican que existe una verdadera renovación del tema de ciudadanía: "ya que el concepto de ciudadanía parece integrar las exigencias de justicia y pertenencia comunitaria, que son respectivamente los conceptos centrales de la filosofía política de los años setenta y ochenta" (KYMLICKA; NORMAN, 1997, p.5).

Como sea, esta 'conquista', aún en su nivel más apasionado o agresivo, implica un sentido de pertenencia en términos de que aquél que 'interpela' por sus derechos se siente parte indudable de esa matriz social 'interpelada'. Sociedad y sujeto se reflejan uno en el otro, desde un modelo social que desde la modernidad keynesiana, preconiza y valoriza la capacidad de escucha y recepción. Matriz social que a su vez se reconoce, como un eco resignificante, en ese sujeto al que se valida como 'interpelador'. Implica entonces, el ser percibido por la sociedad como un interlocutor válido, alguien que tiene o desea tener, un lugar de integración en la misma:

El discurso de la ciudadanía (...) tenía poder performativo no porque necesariamente en la práctica se concretara el principio de igualdad entre los hombres sino porque producía interpelación, deseo de formar parte de esa ficción, de ese universo de discurso, de valores, de principios de prácticas. (DUSCHATZKY, 2002, p.82). 
Desde esta perspectiva esta modernidad es indisociable del concepto de sociedad 'integradora'. Sugerimos entonces que esta estructura de "interlocución" forma parte también del sentido de promesa, discutido más atrás.

La situación de ciudadanía conlleva además a la relación que se establezca entre lo instituido y a lo instituyente a nivel social (así: ¿la ciudadana se otorga o se crea? Idea quizás emparentable a aquélla de Foucault $(1984,1988)$ de que el poder necesita quien lo resista, lo que termina por generar sujetos que no están previstos ni son previsibles en el dispositivo instituido del poder.

Es el pasaje de un esquema de causa-efecto a un paradigma complejizante por el cual el sujeto no es, ni puede ser, igual a los dispositivos instituidos que le conciernen. Es siempre otra cosa que el proyecto que pretendía diseñarlo o que lo atraviesa. Esta alteración o pasaje de lo previsible a lo imprevisible es llamada "subjetivación": “operación capaz de intervenir sobre la subjetividad y el lazo social instituidos" (LEWKOWICZ, 2001, p.21). Por nuestra parte sugeriríamos ampliar esta idea e indicar un fenómeno de ciudadanización que va más allá de la propia ciudadanía, en el sentido de un efecto inédito y otro, no previsto ni previsible en los aparatos estatales correlacionados a la construcción de ciudadanía, Sería un tercer elemento integrante de la promesa: el efecto alteridad.

De esta manera se ha insistido en que la ciudadanización del sujeto tiene que ver con la consolidación de espacios de participación, es decir, privilegiando estrictamente un nivel de lectura política instituida de ciudadanía. Pero ciudadanía implica además capacidad consolidada de cambio, herencia y transformación.

Se podría debatir sobre si la ciudadanía se genera sólo por un proceso de conquistas de derechos sociales o además por una forma de articulación y mediación precisa entre construcción de subjetividad y dinámica social.

Nuestra perspectiva es que ciudadanía no es sólo ganar espacios (como quien "gana" terrenos al mar) sino que además implica una estructura de diálogo ${ }^{2}$, reconocimiento y confianza (aunque sea

\footnotetext{
${ }^{2}$ No nos referimos al diálogo "liberal", sino un diálogo "keynesiano", que no excluye, sin embargo, la persistencia de distintas luchas sociales, pero sí un imaginario de espacios de negociación y encuentro.
}

mínima) dentro de la sociedad, de forma tal que la ciudadanía es un punto de intersección entre aquello que se transmite y aquello capaz de transformación.

Por tanto no es solo "tolerar" socialmente la conquista de derechos justos, es también la expresión de figuras de mediación que establecen pactos y contratos que convalidan una política del intercambio cultural y la exigencia de trabajo psíquico, asentado en el modelo de la segunda tópica freudiana (FREUD, 1923). O sea, ciudadanía no es algo que repose sólo en la realidad "material". Es también realidad "psíquica" y "vincular" que poco tienen de ficción y mucho más de una operatoria social (efectiva) de anticipación y disponibilidad de lugares sociales, que a su vez deben ser transformados por quien los habite. Ubicamos esta operatoria permutativa como el cuarto elemento de la promesa social.

Suponemos así que el conjunto social cumple funciones estructurantes en una red de relaciones intersubjetivas, que a su vez no dejan de influir en la propia sociedad. Sentimiento de pertenencia, reconocimiento y transformación se hacen inseparables y por momentos (estructuralmente) indistinguibles.

Este modelo de ciudadanía se desenvuelve en el percibir al Otro como un semejante. El "otro" en tanto 'vecino', 'patriota', 'amigo', 'colega' o simplemente como 'interlocutor', contextúa un marco de diálogo, de valoración del intercambio que es también co-apuntalante de diversos compromisos sociales, grupales y personales. Esta disponibilidad al 'diálogo' sólo es posible en la medida en que se establece la capacidad de "reconocer" al otro en su alteridad y singularidad y puede relacionarse a lo que Macedo (2003) señala como "razonabilidad pública":

Los ciudadanos liberales deben dar razones que sustenten sus reclamos políticos, en lugar de limitarse a manifestar preferencias o proferir amenazas. Estas razones deben además ser 'públicas' en el sentido de que deben ser capaces de convencer a personas de diferentes creencias y nacionalidades (KYMLICKA; NORMAN, 1997, p.23).

Es desde esta perspectiva que señalamos que persona, Estado y ciudadanía parecen ser inseparables. Podría además pensarse que es en realidad desde la sociedad keynesiana que se logra esta conjunción, y que inclusive esta misma "conjunción” es un elemento meta- estructural de la promesa social. 


\section{El modelo de democracia como paradigma de la representación social}

La democracia moderna presupone que: "las deliberaciones colectivas $[\ldots]$ no son tomadas directamente por quienes forman parte de ella, sino por personas elegidas para este fin" (BOBBIO, 1997, p.52). De esta manera el modelo de democracia es tanto electivo, como delegativo y representativo. No hay democracia sin algún de representación enmarcada en una alta saturación delegativa. Cabe entonces preguntarse hasta que punto el proceso delegativo se constituye en una herramienta coercitiva o en una táctica de control del cuerpo político representativo.

Este modelo de democracia desde el contrato social es esencialmente ambiguo en tanto lo consideramos indisociable, tal como ya indicamos, del par instituyente-instituido. Erigido en capacidad instituyente el voto ciudadano implica "control", "corrección" y capacidad de rectificación. Por el contrario, como efecto instituido, el voto implica un proceso de delegación legitimadora del poder político.

Para Sartori (2000b) existen dos modelos básicos de democracia: la democracia directa, que coincide con la visión clásica, basada en el ejercicio directo del poder político y la democracia representativa, instrumentada a través de una reglamentación jurídica del poder.

Los ideales políticos de la democracia ateniense han sido, desde esta perspectiva, parte fundamental del pensamiento político de occidente (ARENDT, 1966). El concepto de participación ateniense implicaba tomar parte en las funciones legislativas y judiciales participando directamente en los asuntos de la polis.

La democracia ateniense se caracterizaba por un compromiso generalizado con el principio de la virtud cívica: la dedicación a la ciudad-estado republicana y la subordinación de la vida privada a los asuntos públicos y al bien general. [En este contexto,] los derechos y obligaciones del ciudadano estaban relacionados con su posición social; se derivaban de su existencia como ciudadano: eran derechos y obligaciones "públicas". La "vida buena" sólo era posible en la polis. (HELD, 1992, p.32).
En el modelo de democracia clásica ateniense, la asamblea - órgano soberano- estaba constituida por la ciudadanía en su conjunto. Como se sabe, la democracia ateniense se definía, en gran medida, por su carácter exclusivista.

La polis clásica se caracterizaba por su unidad, solidaridad y participación, y por una ciudadanía sumamente restrictiva. El Estado llegaba muy profundamente a la vida de los ciudadanos, pero abarcaba tan sólo a una pequeña porción de la población. (HELD, 1992, p.38).

Para Sartori, la democracia antigua era concebida como "una relación inherente, simbiótica con la polis" (SARTORI, 2000b, p.344) y lo que conocemos como polis griega no constituía lo que ahora entendemos por ciudad-Estado sino más bien, una ciudad-comunidad.

Lo que caracterizaba la democracia de los antiguos era precisamente que era una democracia sin Estado [...]. De ahí que las democracias antiguas no puedan enseñarnos nada sobre la construcción de un Estado democrático y sobre la forma de dirigir un sistema democrático que comprende no una pequeña ciudad, sino una gran extensión de territorio habitado por una enorme colectividad. (SARTORI, 2000b, p.345).

La concepción actual de democracia representativa tiene una influencia innegable del modelo clásico de democracia, sin embargo, sus rasgos definitorios se basan en factores como la tradición republicana ${ }^{3}$, el surgimiento del gobierno representativo y algunas conclusiones derivadas de la creencia en la igualdad política (DAHL, 1992).

Lo que actualmente entendemos por democracia representativa tiene su origen en un sistema de instituciones que inicialmente no era percibido como una forma de democracia o gobierno "por la gente". Para Madison y Siéyès, el gobierno representativo no solo no era un tipo de democracia, sino una forma esencialmente diferente y preferible de

\footnotetext{
El republicanismo surge como una alternativa justa y estable frente a las distintas formas de gobierno, en particular la democracia concebida como una forma inestable de tiranía ejercida por los "muchos" sobre el conjunto de la ciudadanía. La tradición republicana parte del abandono a las formas puras de gobierno (monarquía, aristocracia y democracia) y de la instauración de una forma mixta donde participaran los representantes de todos los estamentos de la ciudadanía en un gobierno estable. De este modo, el republicanismo permitió convertir a la democracia - concebida como una forma de despotismo - en una forma aceptable de participación popular en el gobierno (COTTA, 1988).
} 
gobierno (MANIN, 1997). Asimismo, las prácticas de la democracia moderna guardan poca semejanza con las instituciones políticas de la Grecia clásica, e incluso el concepto mismo guarda poca relación con el desarrollado en el siglo $\mathrm{V}$ antes de nuestra era.

Al igual que los griegos, la tradición republicana adoptó la concepción aristotélica de que "el hombre es un animal social y político". En este contexto, el mejor sistema político debía ser aquel en el cual los ciudadanos fueran iguales ante la ley y entre sí y en el que su legitimidad radicara en la participación del pueblo en el gobierno. Para que esto se verificara se debían concretar al menos tres dispositivos: la noción de Pueblo o lo popular, la noción de Gobierno o gubernamentalidad, y la noción de Ciudadano o ciudadanía.

El gobierno representativo, a pesar de sus críticos ${ }^{4}$ permitió a la democracia convertirse en el paradigma por excelencia aplicable al Estado-Nación, propia de la Época Contemporánea a partir de la Revolución Francesa.

Los procesos de representación se vuelven necesarios en cualquier sociedad compleja y articulada en forma de redes y vínculos, pero no se relacionan necesariamente con el autogobierno popular. La noción de gobierno representativo (PITKIN, 1969) canaliza, tanto como limita las potestades electivas populares. Por eso, y aunque el gobierno representativo se ha vuelto inseparable de la democracia, su historia moderna se inicia como una alternativa consciente al autogobierno popular (MANIN, 1997; GARGARELLA, 1997).

A pesar de que las condiciones objetivas del electorado variaban de Nación a Nación, en todos los casos se tomaron medidas para asegurar que los representantes estuvieran por encima del elector promedio. Lo que contaba no era solamente el status de los representantes, sino también, y de manera más importante, su posición relativa en relación a sus electores. Por lo tanto, ahí donde se gestó el sistema representativo - en Inglaterra, los Estados Unidos y Francia-, éste fue instituido con total conocimiento de causa de que los representantes electos serían, y debían ser, ciudadanos distinguidos "socialmente distintos de aquellos que los habían elegido". Esto es lo que Manin (1997) llama el "principio de distinción".

\footnotetext{
${ }^{4}$ Entre los que destaca Rousseau, quien percibía "an immense gulf between a free people making its own laws and a people electing representatives to make laws for it" (citado por MANIN, 1997:1)
}

Así, aunque comúnmente se considera Manin (1997) que la naturaleza poco democrática del gobierno representativo en sus primeras etapas estribaba en el carácter restringido del derecho al voto, otro elemento igualmente aristocrático del sistema era el método electivo, el cual consistía en diversos arreglos institucionales y circunstancias que aseguraban que los elegidos fueran de un rango superior al de sus electores. El argumento detrás de esta restricción radicaba en la importancia de asegurar que los representantes tuvieran la suficiente independencia económica para ser inmunes a las influencias corruptoras, especialmente aquellas provenientes del ejecutivo (GARGARELLA, 1997).

Lo que garantizaba en este sistema la responsabilidad de los gobernantes no era la semejanza con sus representados sino más bien la ratificación continua de su mandato a través de elecciones frecuentes. En El Federalista, Madison de manera explícita reconoció que la seña distintiva de una República era la delegación del gobierno a unos cuantos ciudadanos elegidos por el resto. Este proceso tenía el efecto de:

refinar y ampliar las opiniones públicas al pasarlas a través de un cuerpo elegido de ciudadanos, cuya sabiduría puede discernir mejor el verdadero interés de su país y cuyo patriotismo y amor a la justicia harán menos probable que lo sacrifique a consideraciones temporales o parciales. (MADISON, FEDERALIST, 10, p.82, 1961).

Sin embargo, y a pesar de sus múltiples virtudes, esta nueva concepción de democracia vinculada a la representación generó sus propios problemas. La asamblea soberana fue sustituida por complejas instituciones políticas que alejaron al gobierno de los representados (DAHL, 1992).

En las sociedades modernas, la representación se presenta en dos formas distintas. Por un lado, se puede entender que el representante es un delegado, es decir, un portavoz, por lo que su mandato es limitado y revocable. Por otro, el representante es un fiduciario, esto es, tiene el poder de actuar con cierta libertad en nombre de sus representados e interpretar sus intereses por lo que no existe obligación de mandato o mandato imperativo (BOBBIO, 1997).

La democracia moderna se basa en el segundo tipo de representación, es decir, se caracteriza por 
entender al representante como un fiduciario que negociador de los intereses generales. Para Manin (1997) la principal diferencia entre los sistemas representativos y los llamados "directos" tiene que ver más con el método de selección que con el número limitado de quienes han sido seleccionados. En este sentido, lo que hace un sistema representativo no es el hecho de que unos pocos gobiernen en el lugar del pueblo, sino que sean seleccionados únicamente por elecciones.

\section{Los procesos de ciudadanía desde la des- contractualización generalizada del neoliberalis- mo de mercado}

Proponemos como hipótesis pensar una nueva forma de contrato social a la que denominamos de descontractualización generalizada, relacionada a modelos políticos impulsados por el neoliberalismo (KLEIN, 2006). Desde este modelo suponemos que el vínculo social pasa por diferentes estados de forma intermitente, quizás relacionable a lo que Bauman sugiere como formas líquidas de lo social (BAUMAN, 1999). Estas formas inéditas de contrato social que propone el neoliberalismo, parecen indicar que los modelos de ciudadanía continúan vigentes, tanto como desaparecen o se ausentan de forma súbita y a veces brutal.

Cabe preguntarse de esta manera si las nuevas formas de democracia que se encuentran en el debate social actual, no implican -paradójicamente- formas de exclusión social. Las mismas estructuras que se encuentran en proceso de asentamiento democrático, sin embargo, no logran solucionar las estructuras de exclusión, que, por el contrario, parecen acentuarse y cronificarse (HELD, 1992; TILLY, 2007). Es decir: desde esta nueva forma de contrato social puede haber democracia sin participación y la misma participación ser una forma de exclusión social. Proponemos llamar a esta modalidad de ciudadanía de: vínculo-no vínculo alternante intermitente.

Cabe aclarar que aunque hay autores que insisten en que no hay ruptura radical entre neoliberalismo y modernidad estatal, creemos que sí hay efectos irreversibles desde aquél con respecto a algunos basamentos que hacen a la modernidad keynesiana. Especialmente en lo referente a las promesas generadas desde la modernidad clásica, en el sentido de homogeneidad, inclusión y generalización. En tal sentido se señala la consolidación de:

Una sociedad heterogénea y fragmentada, surcada por profundas desigualdades de todo tipo- clase, etnia, género, religión, etc.- (...) hay un amplio sector social, un tercio excluido y fatalmente condenado a la marginación y que no puede ser "reconvertido" laboralmente ni insertarse en los mercados de trabajo formales (...) se traduce en desempleo masivo, pobreza extrema, anomia y desintegración social, drogadicción y auge de la criminalidad. (SADER, 1999, p.80-81).

Si lo sólido estatal (LEWKOWICZ, 2004) implicaba un marco desde el cual se reconocía y construía ciudadanía, ley, cultura, responsabilidad y convivencia, lo fluido neoliberal instaura la figura de la impunidad, la transgresión, el extraño y la paranoia. La ley ya no es un referente que cubre y protege a todos, destituida de su lugar de resguardo. En su lugar aparece el convencimiento de que el esfuerzo, la iniciativa, la competencia individual llevan al progreso, debiéndose tolerar un mundo de incertidumbre, de "destitución" de la promesa y la imposibilidad de anticipar un porvenir.

Tomamos la noción de "catástrofe social" como un concepto capaz de describir el estado de desamparo y amenaza que se genera socialmente cuando la figura de la ley es substituida por la figura de la corrupción, la indiferencia o el vacío, lo que enuncia no solo la deslegitimización del aparato jurídico-estatal sino también el agotamiento de las promesas que señalábamos más atrás.

Suponemos así que el neoliberalismo impone una ruptura profunda del contrato social tal como se enuncia en la democracia representativa. Más allá de las distintas permutaciones económicas, sociales y de convivencia, cabe indicar cómo esta nueva modalidad de contrato social o de des-contractualización generalizada implica que el otro se "cotidianiza" bajo las formas de lo ominoso, lo persecutorio, lo angustiante. Las posibilidades de encuentro y comunicación se resienten a favor del enfrentamiento, el recelo y la inseguridad. Lo que lleva a una prevalencia de la vivencia de abandono y, por momentos, incomunicación.

Esta situación consolida la sensación que denominamos de 'catástrofe inminente', como parte de la cultura neoliberal: cualquier cosa pue- 
de pasar en cualquier momento y desde cualquiera (KLEIN, 2006).

Lo que conlleva otra dimensión crucial: la dificultad en asumir como propios los valores de la cultura o al menos los valores de la cultura democrática representativa. La ley de la cultura era o es, inseparable de la idea de justicia e igualdad: "el concepto de ciudadanía parece integrar las exigencias de justicias y de pertenencia comunitaria, que son respectivamente los conceptos centrales de la filosofía política de los años setenta y ochenta" (KYMLICKA; NORMAN,1997, p.5).

Pero además hay que considerar, como ya indicamos, que la ciudadanía es una matriz de convivencia que se desenvuelve dentro de la ilusión eficaz de percibir al otro como un semejante, un reconocible, un - si se quiere- "vecino". Implica, al mismo tiempo, percibir al otro y ser percibido por la sociedad como un interlocutor válido, alguien que tiene o tendrá un lugar en la misma. El otro es un interlocutor con el que se mantiene un marco de diálogo, valoración del intercambio, y formaciones de compromiso sociales, grupales y personales. Por supuesto, siempre y paralelamente, ha existido la figura del otro como enemigo (BAUMAN,1999) pero sugerimos que el modelo neoliberal radicaliza y solidifica la visión del otro como el "extraño", lo que impulsa el miedo y la desconfianza extrema.

Si la eficacia de la ley social se afirma a través de prácticas sociales que aseguran formas de compensación de la desigualdad, podemos decir que lejos de cualquier idea de lo justo, es factible señalar la situación de espantosa desigualdad que viene sobrellevando Latinoamérica (FRAGA, 2003). Esta sociedad neoliberal ya no alberga sino que desampara, decretando el fin de derechos sociales imprescindibles " proponiendo devolver al mercado la regulación de cuestiones como la educación, la salud, la habitación, la previsión social, los transportes colectivos" (COUTINHO, 2000: 66). Es el momento en que ya no se puede sostener un imaginario de derechos "naturales" ya que los derechos escasean, se fragilizan o desaparece la "expectativa" de poder recibirlos.

Consideramos que no sólo la "promesa" emancipatoria (COUTINHO, 2000) no se ha cumplido -como es evidente- sino que además el modelo neoliberal busca desmantelar el marco mismo del vínculo sujeto-sociedad generado desde la modernidad keynesiana. Lo que implica que: "De golpe o paulatinamente se pierde el conocimiento de las reglas que rigen la interacción societaria acerca de la vida y de la muerte, del delito y su penalización" (PUGET, 1991, p.28). Esta situación social por tanto no es simplemente "pérdida" de situaciones consolidadas, es también y simultáneamente la consolidación de nuevas formas de interacción societaria.

Una de estas nuevas formas de interacción societaria se relaciona a la caducidad de la promesa como regulador estatal. El Estado ha pasado de ser una "potencia soberana" (LEWKOWICZ, 2004) a un referente entre otros. Ya no se espera de él garantías, sino que genera (y en esto el neoliberalismo ha tenido un pronunciado protagonismo (SADER, 1999) desencanto y decepción. Se establece, entre lo aquello que se prometió y aquello que se cumplió, un diferencial negativo por el cual el Estado aparece en deuda deficitaria.

Si la ciudadanía es aquella figura de subjetividad que no puede dejar (idealmente) de evaluar, analizar y criticar, encontramos un cambio substancial, por el cual el Estado ya no es un referente de participación social. Es decir, ya no se participa teniendo al Estado como figura referente, sino que se consolidan prácticas participativas que no lo incluyen ni lo interpelan. Cuando el Estado ya no garantiza una promesa no es solamente que se le dejan de pedir cuentas. Otra consecuencia es que progresivamente el Estado deja de ser parte de nuestra cotidianeidad y hasta de nuestra construcción de subjetividad.

Sugerimos así que los procesos de participación política siguen plenamente vigentes, pero ya no garantizan inclusión social, como era propia de las figuras tradicionales de ciudadanía. Un motivo, suponemos, es que los procesos de participación ya no se incluyen dentro de la lógica del lazo estatal. Pero, si la participación está por fuera del lazo estatal y se entiende que el Estado es lo que unifica a la sociedad en términos de ciudadanía entonces entendemos que estas nuevas formas de participación se hacen desde lo fragmentado. Lo que implica al mismo tiempo que así como existe una disociación entre participación política y ciudadanía, también la misma se verifica entre participación política e inclusión social. 
Desde aquí se nos imponen dos reflexiones más:

-Si la participación política se concreta desde lo fragmentado (téngase en cuenta los movimientos homosexuales, feministas, de padres divorciados, reivindicaciones indígenas) es que la lógica participativa se estructura desde las minorías y no desde la mayoría estatal.

-Por otro lado cabe pensar si estas nuevas formas de lazo social no se caracterizan por lo tribal o sea, por el pasaje (o coexistencia) del lazo social estatal al lazo social tribal. En este sentido las figuras del Ágora son sustituidas por las figuras de la aglomeración.

Desde aquí proponemos repensar críticamente las figuras de la des- ciudadanización. Suponiendo que el neoliberalismo logra modificar los mecanismos de representación y participación política, podemos pensar que las formas de "estar-en-sociedad" también cambian. Uno de estos cambios implica que estamos asistiendo a formas de participación desde estructuras democráticas discursivamente válidas pero deslegitimadas como capaces de encontrar soluciones a las problemáticas sociales. Pero si las soluciones a las problemáticas sociales ya no surgen desde el Estado democrático, es que han de surgir otras figuras que den cuenta de esta situación inédita. Probablemente una de estas figuras es la de una ciudadanía - paradójicamente- desvinculada del Estado. Creemos que desde esta perspectiva las llamadas figuras de des-ciudadanización responden en realidad a figuras intermitentes de ciudadanía, que se activan y desactivan selectivamente. O sea: ya no se es ciudadano siempre, ni hay necesidad de serlo siempre, sino selectiva y transitoriamente. Es lo que llamamos ciudadanía de: vínculo-no vínculo alternante intermitente.

\section{Conclusiones: La ciudadanía en tránsito}

Los postulados desarrollados anteriormente nos permiten entender que si bien la situación neoliberal genera cambio profundos en términos de ciudadanía, los mismos responden a procesos más amplios y globales, de tipo multicausal, teniendo en cuenta la reformulación del sentido del Estado, la democracia y los procesos de participación política.

Si desde la modernidad estatal los ciudadanos pueden plantear una regeneración permanente de la sociedad, la trama neoliberal y cultural actual parece sugerir la situación inédita por la cual la participación política ya no implica necesariamente formar parte del lazo social.

De allí que sugerimos que la figura del ciudadano como estructura estable y consolidada se substituye por otras de profunda modificación o tránsito. Ser ciudadano ya no implica necesariamente una continuidad permanente, sino que se pasa a relacionar con procesos puntuales, donde más que una sociedad de ciudadanos nos encontramos ante contextos de ciudadanía.

Este trabajo busca ser una contribución al respecto.-

\section{Referencias}

ANTUNES, R. Crisis capitalista contemporánea y las transformaciones en el mundo del trabajo. In: Capacitaçao em serviço social e politica social: Modulo 1. Brasilia: CEAD, 1999.

ARENDT, H. Los orígenes del totalitarismo. Madrid: Alianza, 1951.

BAUMAN, Z. Modernidade e ambivalencia. Rio de Janeiro: Jorge Zahar, 1999.

BOBBIO, N. El futuro de la democracia. 2.ed. México: FCE, 1997.

COTTA, M. "Parlamentos y Representación” en manual de ciencia política. Salamanca: Alianza Universidad,1988.

DAHL, R. La democracia y sus críticos. Barcelona: Paidós, 1992.

FOUCAULT, M. La ética del cuidado de si como practica de libertad. In: Coleçao ditos \& escritos, 5. Brasil: Política Forense Universitaria, 1988.

Deux essais sur el sujet et le pouvoir. In : DREYFUS H.; RAIBOW, P. Michel Foucault: un parcours philosophique. Francia, Gallimard, 1984.

FRAGA. P. C. P. et al. Jovens en tempo real. São Paulo: DP\&A editora, 2003.

FRANCO, Y. Subjetividad: lo que el mercado se llevó: una perspectiva desde el pensamiento de Cornelius Castoriadis. Disponible en: <www.magma-net.com.ar/subjetividad. htm>.

FREUD, S. El yo y el ello. Amorrortu, v.18, 1923.

El desactivamiento del complejo de Edipo. Amorrortu, v.19, 1924. 
GARGARELLA, R. La crisis de la representación política. México: Fontamara, 1997.

HELD, D. Modelos de democracia. México: Alianza Editorial, 1992.

KLEIN, A. Adolescentes sin adolescência: formas de construcción de la subjetividad adolescente desde el contexto neoliberal. Uruguay: Psicolibros, 2006.

KYMLICKA, W.; NORMAN, W. El retorno del ciudadano: una revisión de la producción reciente en teoría de la ciudadanía. Revista de estudios sobre el Estado y la Sociedad, n.3, Octubre, Paidós, España, p.5-40, 1997.

LEWKOWICZ, I. Pensar sin Estado: la subjetividad en la era de la fluidez, Argentina: Paidós, 2004.

MACEDO, S. Diversity and distrust: civic education in a multicultural democracy Cambridge: Harvard University Press, 2000. Paperback March 2003.

MADISON J. "Federalist 57" y "Federalist 10" En: HAMILTON, A., MADISON, J.; JAY, J. The federalist papers. Nueva York: Penguin, 1961.

MANIN, B. The principles of representative government. Cambridge, Cambridge University Press, 1997.

MARSHALL, T. Ciudadanía, clase social y status. Brasil: Labor, 1967.

MILL, J. S. Consideraciones sobre el gobierno representative. México, Gernika, 1991.

PITIKIN, H. The concept of representation. Berkley: University of California Press, 1984.

PUGET, J.; KAES, R. Violencia de estado y psicoanálisis. Argentina: Centro Editor de América Latina, 1991.

SADER, E.; GENTILI, P. La trama del neoliberalismo: mercado, crisis y exclusión social. Argentina: Universitaria de Buenos Aires, 1999.

SARTORI, G. Teoría de la democracia: el debate contemporâneo. México: Alianza Universidad, 2000a.

Teoría de la democracia: los problemas clásicos. México: Alianza Universidad, 2000b.

TILLY, C. Democracy. Cambridge: Cambridge University Press, 2007. 